\title{
Sinonasal inverted papilloma associated with squamous cell carcinoma
}

\author{
Jasna But-Hadzic¹, Klemen Jenko², Mario Poljak³, Bostjan J Kocjan³, Nina Gale ${ }^{4}$, \\ Primoz Strojan ${ }^{1}$ \\ ${ }^{1}$ Department of Radiation Oncology, Institute of Oncology Ljubljana, Ljubljana, Slovenia \\ ${ }^{2}$ University Department of Otorhinolaryngology and Cervicofacial Surgery, University Clinical Centre Ljubljana, Ljubljana, \\ Slovenia \\ ${ }^{3}$ Institute of Microbiology and Immunology, Medical Faculty, University of Ljubljana, Ljubljana, Slovenia \\ ${ }^{4}$ Institute of Pathology, Medical Faculty University of Ljubljana, Ljubljana, Slovenia
}

Received 21 August 2011

Accepted 1 September 2011

Correspondence to: Prof. Primož Strojan, M.D., Ph.D., Department of Radiation Oncology, Institute of Oncology, Zaloška 2, SI-1000 Ljubljana, Slovenia. Phone: +386 15879 110, Fax: +386 15879 400; E-mail: pstrojan@onko-i.si

Disclosure: No potential conflicts of interest were disclosed.

Background. The aims of the study were to review single-institution experiences with sinonasal inverted papilloma associated with squamous cell carcinoma (IP/SCC), to analyze the presence of human papillomavirus (HPV) and to evaluate the role of radiotherapy.

Patients and methods. Five patients with IP/SCC were identified in the prospective institutional databases (19952005) and HPV status was determined in all five tumors.

Results. Four out of five patients had T3-4 tumors; no nodal involvement was seen in any of them. Four patients had curative surgery, supplemented in three of them with radiotherapy. Debulking surgery was performed in the patient with a non-resectable tumor followed by radical radiotherapy. Tumor was controlled locally in three patients at 8 , 46 and 58 months post-surgery. Local failure occurred in two patients: after endoscopic resection of a T1 tumor (the recurrent tumor was successfully salvaged with additional surgery) and in a patient with an inoperable tumor. No regional or distant metastases occurred. HPV status was determined in all five tumors and three of them were found positive for HPV type 11.

Conclusions. In operable sinonasal IP/SCC, upfront surgery and postoperative radiotherapy to the tumor bed with dose levels comparable to those used for invasive SCC are recommended. For non-resectable disease, radical radiotherapy to a dose of 66-70 Gy could be of benefit.

Key words: inverted papilloma; squamous cell carcinoma; radiotherapy; human papillomavirus infection; outcome

\section{Introduction}

Inverted papilloma (IP, one of three types of Schneiderian papilloma) of the nasal cavity and paranasal sinuses is a benign epithelial tumor of unknown etiology, first described by Ward in $1854 .{ }^{1}$ IP represents $0.5-4 \%$ of all sinonasal tumor and arises from the mucosa of the lateral wall of the nasal cavity, almost always unilaterally. IP is best characterized by the male-to-female ratio of 3:1 with the peak incidence between $5^{\text {th }}$ and $6^{\text {th }}$ decade of life, destructive pattern of local growth, tendency to recur and, occasionally, associated malig- nancy. ${ }^{2,3}$ The most common presenting symptom is unilateral nasal obstruction; the duration of symptoms is variable, with an average of $>5$ years but even up to $>45$ years. $^{2-4}$

The frequency of carcinoma in patients with sinonasal IP is around $11 \%$. In two thirds of cases, carcinoma occurs synchronously with IP, but in some patients carcinoma develops at a later time, after previous resection of IP (metachronous carcinoma). The associated malignancy is predominantly squamous cell carcinoma (SSC), which may arise within the papilloma or is merely associated with a histologically bland IP. ${ }^{2}$ This group of patients is 




FIGURE 1. Inverted squamous papillomas are seen on the right side, synchronous moderately differentiated non-keratinizing invasive squamous cell carcinoma on the left side. thologist (N.G.) (Figure 1) and the medical records of identified patients were reviewed for clinical characteristics, treatment and outcome.

\section{Detection of HPV DNA}

Tissue processing, DNA extraction and quantification as well as HPV detection and genotyping were described elsewhere. ${ }^{7}$ Briefly, total DNA was extracted from two $10-\mu \mathrm{m}$ sections of paraffin blocks using QIAamp DNA FFPE Tissue Kit (Qiagen, Hilden, Germany), following the manufacturer's instructions. For detection of HPV, PCR amplification was performed on all samples using HotStarTaq ${ }^{\circledR}$ Plus DNA Polymerase kit (Qiagen) and consensus GP5+ and GP6+ primers targeting approximately 150-bp fragments of alpha-HPV L1 gene. The PCR products that appeared as visible bands of the expected size were purified by QIAquick PCR Purification Kit (Qiagen) and sequenced directly using BigDye Terminator v1.1 Cycle Sequencing Kit (PE Applied Biosystems, Foster City, USA) with GP5+/GP6+ primers. A comparison of the HPVDNA sequences obtained with those of officially designated alpha-HPV genotypes was carried out using the Blast server. ${ }^{8}$ Results from the Blast comparison software were confirmed additionally by pairwise alignment using the sequence of interest and full L1 gene of a reference HPV genotype. ${ }^{9}$

ance compared with those without associated malignancy. ${ }^{2,3}$ An etiological role for human papillomavirus (HPV) and the mutation of the p53 tumor suppressor gene in malignant transformation of IP has been suggested..$^{5-7}$

Literature reports on IP associated with SCC (IP/ SCC) are scarce, describing only small cohorts of patents treated with varying degree of success. In the present report, we describe a group of five patients treated for IP/SCC. The presence of HPV was analyzed and the role of adjuvant radiotherapy was discussed.

\section{Patients and methods}

The databases of the University Department of Otorhinolaryngology and Cervicofacial Surgery, Clinical Center Ljubljana and the Institute of Pathology, Medical Faculty University of Ljubljana for the years 1995-2005 were used for identification of patients with a diagnosis of IP of the nasal cavity and paranasal sinuses. Out of 89 patients with this diagnosis, 5 patients $(5.62 \%)$ were found to have IP/SCC. Pathology specimens of all 5 patients were re-examined by an experienced head and neck pa-

\section{Results}

\section{Patients and tumors}

Detailed information on the clinical characteristic of patients and their tumors, treatment and outcome is given in Table 1 . There were four males and one female, from 45 to 77 years old (median 73 years). Unilateral nasal obstruction was the most frequent presenting symptom reported by four patients. The duration of symptoms before a diagnosis of IP with or without associated SCC was confirmed ranged from 2-6 months (median: 5 months).

In all but one patient, the disease extended from the nasal cavity to neighboring structures and no nodal or distant metastases were presented at the time of diagnosis in any of them. According to the UICC TNM staging system ( $7^{\text {th }}$ edition, 2009) for malignant tumors of the nasal cavity and ethmoid sinus, four patients had locally advanced T3-4 disease, whereas using the Krouse staging system, ${ }^{10}$ all tumors were categorized as stage T4 (i.e. due to associated malignancy). 
TABLE 1. Sinonasal inverted papilloma associated with squamous cell carcinoma: clinical and tumor characteristics, treatment and outcome

\begin{tabular}{|c|c|c|c|c|c|}
\hline \multirow[t]{2}{*}{ Parameter } & \multicolumn{5}{|c|}{ Patients } \\
\hline & 1 & 2 & 3 & 4 & 5 \\
\hline Sex/Age (yrs.) & $M / 45$ & $M / 77$ & $M / 75$ & $\mathrm{~F} / 73$ & $M / 62$ \\
\hline Presenting symptoms & $\begin{array}{l}\text { Unilateral nasal ob- } \\
\text { struction }\end{array}$ & $\begin{array}{l}\text { Unilateral nasal ob- } \\
\text { struction, nasal dis- } \\
\text { charge, anosmia, pain }\end{array}$ & Nasal discharge & $\begin{array}{l}\text { Unilateral nasal ob- } \\
\text { struction, headache, } \\
\text { diplopia }\end{array}$ & $\begin{array}{l}\text { Unilateral nasal ob- } \\
\text { struction blurred vision, } \\
\text { headache, anopsia }\end{array}$ \\
\hline Duration of symptoms & 6 mos. & 5 mos. & 2 mos. & 2 mos. & 6 mos. \\
\hline $\begin{array}{l}\text { Extent of } \\
\text { disease }\end{array}$ & Lt nasal cavity & $\begin{array}{l}\text { Rt nasal cavity, na- } \\
\text { sopharynx }\end{array}$ & $\begin{array}{l}\text { Rt nasal cavity, eth- } \\
\text { moid, orbit }\end{array}$ & $\begin{array}{l}\text { R† nasal cavity, eth- } \\
\text { moid, maxillary sinus, } \\
\text { orbit }\end{array}$ & $\begin{array}{l}\text { Rt nasal cavity, eth- } \\
\text { moid, fossa pterygopa- } \\
\text { latina, maxillary sinus, } \\
\text { sphenoid, orbit }\end{array}$ \\
\hline TNM stage* & TINOMO & T4bNOMO & T3NOMO & T4aNOMO & T4bNOMO \\
\hline $\begin{array}{l}\text { Histology at } 1^{\text {st }} \\
\text { biopsy }\end{array}$ & $P$ & IP & $P$ & IP & $\mathbb{I P}$ \\
\hline No. of recurrences & 1 & 0 & 1 & 6 & 0 \\
\hline SCC type & $M$ & S & $M$ & $M$ & S \\
\hline $\begin{array}{l}\text { Histpathological grade } \\
\text { of SCC }\end{array}$ & n.s. & G I-III & G $\|-\| \|$ & G॥ & n.s. \\
\hline Surgery & $\begin{array}{l}\text { Endoscopic resec- } \\
\text { tion; RO }\end{array}$ & $\begin{array}{l}\text { Endoscopic resec- } \\
\text { tion; RO }\end{array}$ & Lateral rhinotomy; RO & $\begin{array}{l}\text { Sublabial and external } \\
\text { supraciliar approach; } \\
\text { RO }\end{array}$ & $\begin{array}{l}\text { Sublabial approach, } \\
\text { explorative and de- } \\
\text { bulking procedure; R2 }\end{array}$ \\
\hline HPV status & $\begin{array}{l}\text { Positive } \\
\text { (type 11) }\end{array}$ & $\begin{array}{l}\text { Positive } \\
\text { (type 11) }\end{array}$ & $\begin{array}{l}\text { Positive } \\
\text { (type 11) }\end{array}$ & Negative & Negative \\
\hline Radiotherapy & Not irradiated & $\begin{array}{l}60 \mathrm{~Gy}, 30 \#, 5 \mathrm{MV}, \\
3 \text { fields, continuous } \\
\text { course; Tu site \& Rt } \\
\text { region II }\end{array}$ & $\begin{array}{l}60 \mathrm{~Gy}, 30 \#, 6 \mathrm{MV}, 3 \\
\text { fields, continuous } \\
\text { course; Tu site }\end{array}$ & $\begin{array}{l}60 \mathrm{~Gy}, 24 \#, 5 \mathrm{MV}, 3 \\
\text { fields, continuous } \\
\text { course; Tu site \& R† } \\
\text { neck }\end{array}$ & $\begin{array}{l}70 \text { Gy, 35\#, } \\
\text { Co-60, } 3 \text { fields, contin- } \\
\text { uous course; Tu site }\end{array}$ \\
\hline Follow-Up & $\begin{array}{l}\text { Local recurrence at } 8 \\
\text { mos., NED } 62 \text { mos. af- } \\
\text { ter salvage surgery }\end{array}$ & $\begin{array}{l}\text { DOC at } 46 \text { mos., no } \\
\text { evidence of IP/SCC }\end{array}$ & NED at 58 mos. & $\begin{array}{l}\text { DOC at } 8 \text { mos., no evi- } \\
\text { dence of IP/SCC }\end{array}$ & $\begin{array}{l}\text { DOD at } 14 \text { months, } \\
\text { locally progressive } \\
\text { disease }\end{array}$ \\
\hline
\end{tabular}

M - Male; F - Female; Rt - Right; Lt - Left; P - Papilloma; IP - Inverted papilloma; M - Metachronous; S - Synchronous; n.s. - Not specified; SCC - Squamous cell carcinoma; \# - No. of fractions; Tu - Tumor. NED - No evidence of disease; DOD - Died of disease; DOC - Died of other cause.

*TNM clinical classification of malignant tumors of the nasal cavity and ethmoid sinuses.

The presence of SCC was confirmed by histopathological examination of resected specimen (i.e. after a biopsy proved negative for the presence of SCC) in two patients (pts. 2 and 5). The other three patients had metachronous SCC found in recurrent IP at 3, 10 and 24 years after first surgery (in pt. 4 at the time of resection of the sixth recurrence of IP). An invasive SCC component was found in all cases.

\section{Treatment}

Four patients were operated on with curative intent. The surgical technique was dictated by the extent of the disease: a transnasal endoscopic technique and an external approach were used in two patients each. Surgery was declared as radical, without microscopic residual disease left behind, in all four patients, and all but one were irradiated postoperatively. The patient with extensive local disease, extending to the right ethmoid complex, sphenoid, pterygopalatinal fossa and orbita, had only debulking surgery followed by radiotherapy as a definitive treatment. None of the patients received systemic chemotherapy.

Postoperatively, continuous-course radiotherapy of 5 fractions per week was delivered in three patients, using megavoltage 5-MV or 6-MV linear accelerator photon beams, to a total tumor dose of $60 \mathrm{~Gy}$. In two patients, the daily dose was $2 \mathrm{~Gy}$ and in one patient $2.5 \mathrm{~Gy}$ per fraction. The patient with gross residual disease after surgical debulking received definitive radiotherapy using megavoltage Co-60 photons in daily fractions of 2 Gy to a total dose of $70 \mathrm{~Gy}$. Two-dimensional computerbased planning was used to cover the postopera- 
tive tumor bed or gross tumor volume including sinuses at risk for containing microscopic disease with a $\geq 95 \%$ isodose curve. A conventional threefield technique employing a heavily weighted anterior field and two opposed lateral wedged fields to achieve dose homogeneity in the range of $\pm 5 \%$ inside the treated volume, head holders with thermoplastic casts and individual shielding blocks were used. When appropriate, optic structures were shielded after a dose of $54 \mathrm{~Gy}$. The ipsilateral regional lymphatics (regions II-V) were irradiated postoperatively in one patient (pt. 5), through an anterior field and with 2.5 daily fractions to a total dose of $40 \mathrm{~Gy}$, whereas in another patient (pt. 2), region II was covered ipsilaterally to a dose of $50 \mathrm{~Gy}$ in 2-Gy daily fractions. In both patients, indication for neck irradiation was extensive local disease.

\section{Outcome}

After diagnosis of IP/SCC, two patients were alive at 58 and 70 months. In the patient treated solely with endoscopic resection (patient 1), isolated local recurrence, histologically confirmed as IP/SCC, developed on the nasal septum 8 moths later; an endoscopic salvage procedure resulted in a permanent local control of 62 months. Two patients died of disease-unrelated causes without disease reappearance at 8 and 46 months after diagnosis of IP/ SCC; at the time of death, they were 74 and 81 years old, respectively. The patient who underwent definitive radiotherapy died due to progression of residual disease at 14 months from biopsy.

No severe or unexpected complications of treatment were documented during therapy and none of the patients had severe late therapy-related sequelae that would demand surgical intervention or hospitalization.

\section{Human papillomavirus}

Three out of five tumors analyzed for the presence of HPV were found positive, with type 11 being present in all positive cases.

\section{Discussion}

In IP, whether or not associated with SCC, complete surgical removal of the tumor is advocated as the treatment of choice. Endoscopic treatment is preferred, whereas for lesions less accessible endoscopically, or in those with peripheral extension, open surgery is indicated. ${ }^{11,12}$ When complete resection is not possible, or for tumors with associated malignancy, radiotherapy is recommended as an adjunct to surgery. ${ }^{13,14}$

While the experiences with IP are extensive $e^{4,10-12}$, series describing IP/SCC are limited and feature a limited number of cases. Tanvetyanon et al. ${ }^{15} \mathrm{col}-$ lected survival data of 76 patients from his series and ten additional series published during the last 30 years, covering a recruitment period of almost six decades. ${ }^{4,13-22}$ The corresponding pooled median overall survival was 126 months with 3-year survival estimate of $63 \%$, which is in the range reported for invasive SCC of the nasal cavity and paranasal sinuses ${ }^{23}$ but much lower compared to figures appearing in IP series. ${ }^{4,11,12}$

Recommendations for the use of radiotherapy are based on clinical observations rather than scientific analyses. More than three quarters of 76 patients from pooled group reported by Tanvetyanon et al. had one or another form (i.e. pre- or postoperative, definitive, palliative) of irradiation but no analysis on the value of radiotherapy versus surgery alone was carried out in their study. ${ }^{15}$ After detailed review of the studies analyzed in the paper mentioned above, we conclude that the low quality of information on the tumor extent and treatment, including completeness of surgical resection, in some publications must be the reason.

According to Hug et al. ${ }^{13}$ and Gomez et al. ${ }^{14}$, the probability of regional or systemic dissemination of IP/SCC is low. Consequently, they proposed elective irradiation of regional lymphatics only in patients with extensive involvement of the nasopharynx or clinically or radiologically apparent neck metastases. Our limited experience corroborates their recommendations.

Because of generally accepted opinion that radiotherapy should not be used as an adjunct to surgery in bland IP, in IP/SCC cases the choice of irradiation dose level is usually dictated by the recommendations for invasive SCC. This is obviously the case when series with sufficiently described radiotherapy details are reviewed. ${ }^{14,15,17,20}$ In 19 pre- or postoperatively irradiated patients, radiotherapy doses ranged from 45 Gy to 70.4 Gy (median $60 \mathrm{~Gy}$ ); all but four patients received 58.4-66.8 Gy. Furthermore, in a group of 13 patients with IP/ SCC reported by Hugh et al. ${ }^{13}$ only one local failure occurred after gross total resection and adjuvant hyperfractionated or conventionally fractionated radiotherapy to a mean dose of $59 \mathrm{~Gy}$ or $60 \mathrm{~Gy}$, respectively. Following subtotal resection, one out of three tumors failed locally after hyperfractionated irradiation to a mean dose of $66 \mathrm{~Gy} .{ }^{13}$ In the present 
series, all three tumors postoperatively irradiated were locally controlled at 8,46 and 58 months postdiagnosis; an irradiation dose of $60 \mathrm{~Gy}$ was adjusted to the tumor stage (T3-T4) and the presence of the SCC component.

Experience with chemotherapy in IP/SCC is very scarce. In the majority of cases, chemotherapy was aimed at palliating symptoms of unresectable disease, locally or at distant sites, ${ }^{15,20}$ or has exceptionally been used for reducing tumor size before surgery $^{15,21}$, or in a postoperative setting, usually with irradiation. ${ }^{15,19-21}$ The chemotherapeutics used were platinum compounds, 5-fluorouracil, paclitaxel, etoposide, and methotrexate. ${ }^{15,21}$ No conclusions could be made on the effectiveness of chemotherapy in SCC/IP; however, none of the three patients with distant metastases reported by Tanvetyanon et al. ${ }^{15}$ responded to any of the chemotherapy regimens used.

Presence of HPV type 11 was confirmed in three out of five tumors from the present series. Similarly, Cheung et al. ${ }^{5}$ demonstrated the presence of HPV in four out of seven IP/SCC cases, one of them being type 11 (typing was not done in other cases because of inadequate HPV DNA content). Simultaneously decreased expression of $\mathrm{p} 16$ found in above cited and other studies indicates that the role of HPV in the oncogenesis of IP/SCC differs from that in cervical SCC. It seems that HPV infection occurs as an early event in the multistep process of malignant transformation from IP to SCC. $5,6,24$ However, others suggested that HPV infection may represent incidental colonization rather than being and important etiological factor. ${ }^{7}$

Rather high prevalence of HPV infection in IP but also IP/SCC specimens poses clinically relevant question on the potential prognostic significance of HPV status. Patients with HPV-positive SCCs of the head and neck, oropharynx in particular, have superior outcome, attributed to enhanced radiation and chemo-sensitivity due to an intact apoptotic mechanism in response to radiation and chemotherapy. ${ }^{25,26}$ Because in oropharyngeal SCCs HPV types 16 and 18 rather than 11 are usually found, the question of radio/chemo-sensitivity of HPVpositive IPs and IP/SCCs at this point remains to be elucidated. However, unexpectedly favorable responses after radiotherapy have also been reported in extensive IPs and SCC/IPs. Myers et al. ${ }^{17}$ described a case of IP/SCC destroying the bony walls of the antrum with orbital invasion; no residual IP or SCC was found in the surgical specimen after 60 Gy of preoperative radiotherapy. A similar experience with preoperative irradiation was reported by
Gomez et al. ${ }^{14}$, whereas in the patient with non-resectable IP with bilateral involvement of the nasal cavity and paranasal sinuses, radiotherapy alone with 65 Gy was deemed curative (no recurrence at 7 years). The authors draw attention to the rather long interval after irradiation, from 3 to 6 months, for gross disease to disappear. ${ }^{14}$ Also, after surgical debulking of locally recurrent IP associated with carcinoma in situ, affecting the zygomatic area and with extension into the infratemporal fossa, Levendag et al. ${ }^{27}$ found irradiation to 64 Gy highly effective, resulting in complete regression of the lesion for almost one year.

\section{Conclusions}

According to clinical experiences, combination of surgery and postoperative irradiation with radiotherapy dose levels in a range used for invasive SCC are recommended for operable IP/SCC. Elective neck irradiation should be considered only for patients with extensive nasopharyngeal involvement or apparent regional metastases. For non-resectable disease, radical radiotherapy to a dose of 66-70 Gy could be of benefit with potential for long-lasting remission or even cure.

\section{Acknowledgement}

A study was supported by Slovenian Research Agency Grant P3-0307.

\section{References}

1. Ward N. A mirror of the practice of medicine and surgery in the hospitals of London: London hospital. Lancet 1854; 2: 480-2.

2. Barnes L. Schneiderian papillomas and nonsalivary glandular neoplasms of the head and neck. Mod Pathol 2002; 15: 279-97.

3. Eggers G, Muhling J, Hassfeld S. Inverted papilloma of paranasal sinuses. J Craniomaxillofac Surg 2007; 35: 21-9.

4. Vrabec DP. The inverted Schneiderian papilloma: a 25-year study. Laryngoscope 1994; 104: 582-605.

5. Cheung FMF, Lau TWS, Cheung LKN, Li ASM, Chow SK, Lo AWI. Schneiderian papillomas and carcinomas: a retrospective study with special reference to $\mathrm{p} 53$ and p16 suppressor gene expression and association with HPV. Ear Nose Throat J 2010; 89: E5-12.

6. Kim SG, Lee OY, Choi JW, Park YH, Kim YM, Yeo MK, et al. Pattern of expression of cell cycle-related proteins in malignant transformation of sinonasal inverted papilloma. Am J Rhinol Allergy 2011; 25: 75-81.

7. Jenko K, Kocjan B, Zidar N, Poljak M, Strojan P, Žargi M, et al. In inverted papilloma HPV more likely represents incidental colonization than an etiological factor. Virchows Arch (in press).

8. The National Center for Biotechnology Information Database [http://www. ncbi.nlm.nih.gov/blast/] 
9. The European Molecular Biology Open Software Suite [http://www.ebi. ac.uk/emboss/]

10. Krouse JH. Development of a staging system for inverted papilloma. Laryngoscope 2000; 111: 965-8.

11. Lawson W, Patel ZM. The evolution of management for inverted papilloma: an analysis of 200 cases. Otolaryngol Head Neck Surg 2009; 140: 330-5.

12. Lombardi D, Tomenzoli D, Buttà L, Bizzoni A, Farina D, Sberze F, et al. Limitations and complications of endoscopic surgery for treatment for sinonasal inverted papilloma: a reassessment after 212 cases. Head Neck 2011; 33: 1154-61.

13. Hug EB, Wang CC, Montgomery WW, Goodman ML. Management of inverted papilloma of the nasal cavity and paranasal sinuses: importance of radiation therapy. Int J Radiat Oncol Biol Phys 1993; 26: 67-72.

14. Gomez JA, Mendenhall WM, Tannehill SP, Stringer SP, Cassisi NJ. Radiation therapy in inverted papillomas of the nasal cavity and paranasal sinuses. Am J Otolaryngol 2000; 21: 174-8.

15. Tanvetyanon T, Qin D, Padhya T, Kapoor R, McCaffrey J, Trotti A. Survival outcomes of squamous cell carcinoma arising from sinonasal inverted papilloma: report of 6 cases with systematic review and pooled analysis. Am J Otolaryngol 2009; 30: 38-43.

16. Yamaguchi KT, Shapshay SM, Incze JS, Vaughan CW, Strong S. Inverted papilloma and squamous cell carcinoma. J Otolaryngol 1977; 8: 171-8.

17. Myers EN, Schramm VL, Barnes EL. Management of inverted papilloma of the nose and paranasal sinuses. Laryngoscope 1981; 91: 2071-84.

18. Myers EN, Fernau JL, Johnson JT, Tabet JC, Barnes EL. Management of inverted papilloma. Laryngoscope 1990; 100: 481-90.

19. Segal K, Atar E, Mor C, Har-El G, Sidi J. Inverting papilloma of the nose and paranasal sinuses. Laryngoscope 1986; 96: 394-8.

20. Lesperance MM, Esclamado RM. Squamous cell carcinoma arising in inverted papilloma. Laryngoscope 1995; 105: 178-83.

21. Shipchandler TZ, Batra PS, Citardi MJ, Bolger WE, Lanza DC. Outcomes for endoscopic resection of sinonasal squamous cell carcinoma. Laryngoscope 2005; 115: 1983-7.

22. Oikawa K, Furuta Y, Itoh T, Oridate N, Fukuda S. Clinical and pathological analysis of recurrent inverted papilloma. Ann Otol Rhinol Laryngol 2007; 116: 297-303.

23. Dulguerov $P$, Jacobsen $M S$, Allal AS, Lehmann $W$, Calcaterra $T$, Nasal and paranasal sinus carcinoma: are we making progress? A series of 220 patients and a systematic review. Cancer 2001; 92: 3012-29.

24. Kim JY, Yoon JK, Citardi MJ, Batra PS, Roh HJ. The prevalence of human papilloma virus infection in sinonasal inverted papilloma specimens classified by histological grade. Am J Rhinol 2007; 21: 664-9.

25. Marur S, D'Souza G, Westra WH, Forastiere AA. HPV-associated head and neck cancer: a virus-related cancer epidemic. Lancet Oncol 2010; 11: 781-9.

26. Ragin CC, Taioli E. Survival of squamous cell carcinoma of the head and neck in relation to human papillomavirus infection: review and meta-analysis. Int J Cancer 2007; 121: 1813-20.

27. Levendag PC, Annyas AA, Escajadillo R, Elema JD. Radiotherapy for inverted papilloma: a case report. Radiother Oncol 1994; 2: 13-7. 